\title{
VERSOS DE MEDIÇÃO GRECO-LATINA EM "VEM SENTAR-TE COMIGO, LÍDIA, À BEIRA DO RIO" DE RICARDO REIS
}

\author{
Verses of Graeco-latin measuring \\ in "Vem sentar-te comigo, Lidia, \\ à beira do rio", by Ricardo Reis
}

\author{
Érico Nogueira*
}

\begin{abstract}
RESUMO
Este artigo é um breve estudo dos princípios métrico-rítmicos que presidiram à composição da ode "Vem sentar-te comigo, Lídia, à beira do rio", de Ricardo Reis. Partindo, primeiro, da consideração dos mais conhecidos métodos de aclimatação de medidas greco-latinas empregados por poetas e tradutores lusófonos, depois, dos apontamentos do próprio Pessoa sobre a matéria, pretende-se, ao fim e ao cabo, caracterizar a singularidade da métrica utilizada por ele na referida ode.
\end{abstract}

Palavras-chave: métrica clássica; versificação vernácula; imitação; poética. 


\begin{abstract}
This paper is a brief study on the metrical principles underlying the ode "Vem sentar-te comigo, Lídia, à beira do rio", by Ricardo Reis. Considering, first, the most common methods of imitating classical metrics in Portuguese, second, Fernando Pessoa's own observations on the matter, we intend to describe and better understand the metric principles he used in the aforementioned ode.
\end{abstract}

Keywords: quantitative metrics; versification; imitation; poetics.

\title{
1. INTRODUÇÃo
}

Escusando-nos de fazer uma história exaustiva das aclimatações de versos e estrofes greco-latinos ao português - assunto algo extenso já parcialmente tratado em outro artigo ${ }^{1}$-, convém observar, muito rapidamente, que tal história divide-se em duas fases. Remonta, a primeira delas, ao século XVIII, e à produção pioneira de José Anastácio da Cunha². Continua, século XIX adentro, com Vicente Pedro Nolasco da $\mathrm{Cunha}^{3}$ - o mais representativo desta fase inicial -, e, passando por outros nomes, chega, ainda no mesmo século, a Júlio de Castilho ${ }^{4}$ (filho de Antônio Feliciano), que inaugura sua segunda fase. Tanto quanto pudemos averiguar, os princípios prosódicos utilizados por Castilho têm orientado, desde então, a quase totalidade das empresas do gênero ${ }^{5}$, incluindo a maior e mais importante de todas, que é a tradução hexamétrica da Ilíada, Odisseia e Eneida, de Carlos Alberto Nunes.

Numa palavra, o que distingue as duas fases entre si é o método que poetas e tradutores empregam na aclimatação vernácula dos versos em questão. Na primeira, trata-se ou bem de seguir as regras métrico-prosódicas do latim, língua-mãe do português, fundadas na quantidade silábica (o método de Anastácio), ou bem de estabelecer teoricamente e poetar de facto com

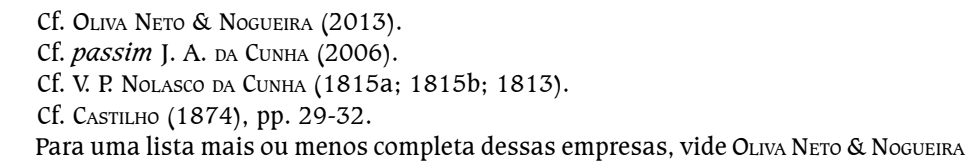


quantidades silábicas supostamente portuguesas (o método de Nolasco). $\mathrm{Na}$ segunda, a regra é, digamos, "traduzir" a prosódia clássica na vernácula, interpretando a sílaba longa grega ou latina como tônica ou subtônica portuguesa, e como átona a sílaba breve - e isso já por justaposição de metros vernáculos tradicionais, como, por exemplo, o hexâmetro de Magalhães de Azeredo (constante de um hexassílabo e um octossílabo) ${ }^{6}$, já pelo rigoroso encadeamento de células métricas variadas, como as Píticas de Píndaro na recentíssima tradução de Leonardo Antunes ${ }^{7}$. Conquanto possam entender-se como variação do segundo método, as odes heterométricas de Ricardo Reis ${ }^{8}$, cujo exemplo mais complexo e acabado é justamente "Vem sentar-te comigo, Lídia, à beira do rio", foram as únicas exceções que pudemos identificar. Senão vejamos.

Preliminarmente à consideração dessa ode - ou antes de seus característicos métrico-rítmicos que se podem interpretar, segundo veremos, como singular tentativa de reprodução vernácula de versos greco-latinos -, é preciso dizer, com Fernando Lemos, que

Catalogado como Envelope 122 do espólio de Fernando Pessoa, intitulado Métrica, encontra-se um texto a ocupar 44 folhas numeradas, que apresentam as mesmas características do restante acervo: coexistência de fragmentos, uns manuscritos, muitas vezes difíceis de decifrar, com outros dactilografados, marcas de projecto inacabado, suportes materiais de escrita diversificados no tamanho e na qualidade. Quanto me pude informar, todo esse material tem permanecido inédito, talvez por estar directamente relacionado com o heterónimo menos estudado, Ricardo Reis. Não é difícil descobrir que, apesar de não estarmos em presença de um texto sequente prestes a ser dado ao prelo, informa-o a perspectiva clássica greco-romana que individualiza e unifica ambas as componentes: a reflexão teórica e o tratado de prosódia e poética, em que se põem à prova, com exemplos práticos, as regras de quantidade formuladas para a língua portuguesa e se estudam os acentos rítmicos nos mais importantes metros praticados por Horácio. ${ }^{9}$

6 Cf. Magalhães de Azeredo (1904), p. 59.

7 Cf. passim Antunes (2012).

8 Fernando Pessoa publicou em vida apenas vinte e oito de um total de duzentas e vinte duas odes que, segundo SiLva BéLKIor (1988) em estudo já clássico, constituem o inteiro corpus de Ricardo Reis. Desse total - cuja imensa maioria, no tocante à métrica, é combinação de decassílabo com hexassílabo, diga-se de passagem -, apenas nove são heterométricas, a saber: 1) "Vem sentar-te comigo, Lídia, à beira do rio"; 2) "A palidez do dia é levemente dourada"; 3) "Não tenhas nada nas mãos"; 4) "Da lâmpada noturna"; 5) "Não a ti, Cristo, odeio ou te não quero"; 6) "Não porque os deuses findaram, alva Lídia, choro"; 7) "A mão invisível do vento roça por cima das ervas"; 8) "Quando Netuno houver alongado"; e 9) "Tu, Apolo, dá-me o número e o ritmo".

91993 , p. 15. 
Editado por Lemos como apêndice ao estudo onde se lê o que vai acima, o Envelope 122 é literalmente um achado. Quando menos, porque - se nos for lícito parafrasear, invertendo-o embora, o famoso conselho de Bilac - ele nos mostra os andaimes que presidiram à construção do edifício poético de Reis, cujo classicismo não se resume, em matéria de métrica, a reproduzir os cânones do horacianismo lusitano.

Ora, sem considerar a origem e o desenvolvimento da ode em português - assunto que evidentemente excede o escopo deste artigo -, o certo é que desde Luís de Camões e Antônio Ferreira, passando por Correia Garção, Filinto Elísio e Elpino Duriense, entre outros, a ode tem se caracterizado, preponderante e quase exclusivamente, por combinação mais ou menos variável de decassílabo com hexassílabo, a qual, por sua vez, se permite certa variação rítmica e estrófica, nos parece bastante aquém da rica variedade métrica das odes de Horácio com que pretende emular. Também em Ricardo Reis tal combinação prepondera, sem dúvida, e constitui a face, digamos, mais convencional e bem-comportada de sua produção - de cuja monotonia, porém, o próprio Pessoa parecia ciente quando redigiu a famosa crítica de Álvaro Campos ao horaciano:

Não concebo, porém, que as emoções, nem mesmo as do Reis, sejam universalmente obrigadas a odes sáficas ou alcaicas, e que o Reis, quer diga a um rapaz que lhe não fuja, quer diga que tem pena de ter que morrer, o tenha forçosamente que fazer em frases súbditas que por duas vezes são mais compridas e por duas vezes mais curtas, e em ritmos escravos que não podem acompanhar as frases súbditas senão em dez sílabas para as duas primeiras, e em seis sílabas as duas segundas, num graduar de passo desconcertante para a emoção. ${ }^{10}$

Eis o ponto: inserindo-se conscientemente em tradição, como vimos, nascida no século XVIII ${ }^{11}$, há uma face desconhecida e talvez por isso

10 Cf. PEssoa (1974), p. 141.

11 Uma surpreendente observação de Pessoa sobre José Anastácio da Cunha nos revela que conhecia suas traduções hexamétricas de Gessner: "Da transformação literária, representada por um rompimento definido com as tradições literárias portuguesas, pode-se considerar ponto de partida Antero de Quental e a escola de Coimbra, embora necessariamente precedida de prenúncios e tentativas de tal modificação remontando até 1770 , ao esquecido José Anastácio da Cunha (poeta superior ao exageradamente apreciado e insuportável Bocage): José Anastácio, com a sua cultura complexa (além do costumeiro francês, sabia inglês e alemão e traduzia Shakespeare, Otway e Gessner), representa o primeiro lampejo da alvorada no horizonte da literatura portuguesa, pois constitui a primeira tentativa de dissolver a forma endurecida da estupidez tradicionalista pelo processo usual dos múltiplos contactos culturais". (Op. cit., pp. 419-420). Considerando-o, pois, justa ou injustamente, um poeta superior a Bocage e o primeiro renovador da poesia lusa, é de supor que Pessoa atribuísse o mesmo sentido de dissolução da "estupidez tradicionalista" às odes de Ricardo Reis compostas na tradição de Anastácio. 
mesmo moderna do heterônimo Ricardo Reis (tido, em geral, por simples arcaizante), cuja atividade acolhe o incremento de ritmos e metros vernáculos mediante a emulação de seus congêneres latinos, e, pois, inclui a heterometria, e com ela certa variação dos ritmos tradicionais, no rol da poesia rigorosamente metrificada e, numa palavra, "clássica".

Partindo, pois, do referido estudo de Fernando Lemos, para quem "o manuscrito Métrica é suficientemente esclarecedor dos vários aspectos na evolução da prática poética de Ricardo Reis e representará a sua primeira fase" ${ }^{12}$, o que pretendemos, primeiro, é fazer breve rol das observações teóricas e dos principais metros clássicos que Pessoa estuda e pratica no referido manuscrito, e, depois, - senda que Lemos abriu, mas deixou inexplorada - identificar o metro de Horácio que está na base de "Vem sentar-te comigo, Lídia, à beira do rio", cujo método de composição desejamos elucidar.

\section{O ENVELope 122}

2.1) Folha 13, p. $103^{13}$.

Nesta folha, pode ler-se claramente um plano de trabalho de um tratado de métrica que infelizmente ficou só no plano. Não um tratado convencional, contudo, senão que exclusivamente voltado à fabricação vernácula de versos greco-latinos. O plano consta de oito itens. O de número oito - precisamente o que mais nos interessa, uma vez que esclarece, em certa medida, o método de composição das odes heterométricas de Ricardo Reis, e de "Vem sentar-te comigo, Lídia, na beira do rio" em especial - chama-se "Da Simulação Acentual do Verso Quantitativo". Se pudermos, pois, desde já, adiantar o conteúdo do Envelope, que aqui selecionamos e resumimos bastante, é preciso dizer que Pessoa oscila entre a) atribuir quantidades precisas ao português; $b$ ) valer-se da tonicidade e atonicidade do português para simular a longura e a brevidade silábicas do latim; e c) mapear os acentos intensivos do verso latino e tentar reproduzi-los no vernáculo. As odes heterométricas de Ricardo Reis, em particular a que analisaremos detalhadamente em breve, mostram que optou pela última via. É esta, não outra, a sua principal novidade neste quesito, a qual lhes confere um lugar à parte, sem dúvida, na história da aclimatação de medidas clássicas à nossa língua.

13 Damos aqui o número original da folha, seguido da página em que Lemos a estampou em sua edição. 
2.2) Folha 14, p. 104.

Tradução hexamétrica do começo da Eneida:

Armas e o varão | eu canto que vindo de Troia

À costa italiana | primeiro impulso da sorte

E à Lavínia chegou | em mar e terra agitada [...].

O excerto é composto à maneira de Castilho, isto é, simulando a longura e a brevidade silábica do original, respectivamente, pela tonicidade e atonicidade das sílabas vernáculas. Tônicas em negrito.

2.3) Folha 19, p. 108.

a) Epodo [trímetro e dímetro]:

Raras | se tor $\mid$ nam,$\backslash$ ma $\mid$ ga das | belas | horas,

Já as | visi | tas lú|cidas. [...]

Este poema, de que transcrevemos apenas o dístico inicial - um trímetro e um dímetro jâmbico, respectivamente, cujas longas marcamos em negrito - é composto à maneira do citado Nolasco da Cunha, isto é, com quantidades silábicas teoricamente portuguesas. No que toca a Fernando Pessoa, constitui o exemplo mais acabado do primeiro e mais antigo método de aclimatação vernácula de versos greco-latinos.

b) Tradução da primeira linha da primeira bucólica de Virgílio segundo o método de Castilho:

Títiro tu estendido | à sombra lá da árvore larga.

2.4) Folha 21, p. 110.

Tradução do início da Arte Poética de Horácio segundo um método misto - o primeiro verso à Castilho, o segundo à Nolasco e o terceiro à Castilho de novo:

A uma cabeça humana | se juntasse um pintor [...]

Pescoço e penas | despois juntasse em seguida

Membros de um animal | uns e outros de outro animal [...]. 
2.5) Folha 26, p. 114

Hexâmetros soltos compostos à Castilho. São quiçá os melhores de Pessoa:

Ondas do mar infindas | perturbadamente batendo

Ontem hoje amanhã | fendendo rochedos e abrindo [...]

Verme da terra que ligas | amor aos céus e às estrelas

Teus olhos ondeiam | mesquinhos, ó verme da terra.

2.6) Folha 28, p. 115-116.

a) Esta é a mais importante observação teórica de Pessoa, que nos permitirá, aliada ao que leremos nos dois próximos itens e na folha 29 , compreender e analisar com justeza o método de aclimatação de medidas latinas que empregou em "Vem sentar-te comigo, Lídia, à beira do rio" e em todas as odes heterométricas. Como já dissemos acima, trata-se, inicialmente, de mapear a incidência dos acentos intensivos dos poemas latinos para, em seguida, tentar reproduzir ou adaptar tal incidência em português:

Hexâmetro: (5 ou 6) seis acentos. [Negrito do autor.]

Pentâmetro: $5(2+3)$.

Trímetro 4 ou $5(2+3)$.

Dímetro: 3.

b) Ode I, 1 de Horácio: Pessoa estuda a posição e assinala os acentos intensivos dos versos asclepiadeus.

c) Ode I, 9 de Horácio: Pessoa estuda a posição e assinala os acentos intensivos dos hendecassílabos alcaicos.

2.7) Folha 29, p. 117-118.

a) Pessoa estuda a posição e assinala os acentos intensivos do hexâmetro: cinco ou seis acentos em posição mais ou menos variável.

b) Pessoa estuda a posição e assinala os acentos intensivos dos oito primeiros versos da ode I, 11 a Leucônoe, de Horácio, composta em asclepiadeus maiores. Como o hexâmetro, também o asclepiadeu maior consta de cinco ou seis acentos em posição mais ou menos variável, embora ligeiramente distinta daquele.

c) Pessoa estuda a posição e assinala os acentos intensivos da estrofe sáfica. 
2.8) Folha 33, p. 123.

Tradução hexamétrica do início do $4^{\circ}$ canto das Geórgicas segundo o método de Castilho, com anacruse no segundo verso:

Cabe-me o dom divino | do mel aéreo agora

Cantar: a ti consagro | Mecenas também esta parte.

\section{Versos Asclepiadeus Maiores em "Vem sentar-te comigo, Lídia, À BEIRA DO RIO"}

Segundo pudemos verificar a partir de brevíssimo resumo do Envelope 122, Fernando Pessoa não só conhecia e dominava os dois métodos mais comuns de aclimatação de medidas clássicas a uma língua moderna, senão também desenvolveu um seu método particular, que consiste, primeiro, em observar o número e a posição dos acentos intensivos do verso ou estrofe latina em questão e, segundo, em fabricar poemas portugueses que bem ou mal reproduzam os dados observados.

Tendo, pois, em mente o conteúdo do dito Envelope, leiamos agora, primeiro segundo a contagem tradicional de sílabas poéticas, depois assinalando o número e posição dos acentos de intensidade, a ode "Vem sentar-te comigo, Lídia, à beira do rio" - a maior, mais complexa e mais perfeita entre todas as heterométricas. Feito isso, leiamos também, respectivamente segundo a leitura escolar da métrica quantitativa e em seguida marcando os seus acentos intensivos, a ode I, 11 a Leucônoe, de Horácio, que Pessoa estudou minuciosamente. Como poderemos verificar então, a semelhança entre os poemas radica no número e na posição de seus acentos de intensidade - ou seja, o que a comparação entre ambos, a partir de diversos métodos de leitura e escansão, acaba por revelar é que o princípio compositivo de Pessoa-Reis, à diferença de todos os seus antecessores e sucessores de que temos tido notícia, é simulação vernácula do número e posição dos acentos intensivos do original ${ }^{14}$. E aqui convém fazer uma última observação antes da leitura. $\mathrm{Se}$, nalguns casos, é relativamente fácil identificar o metro ou estrofe de

14 Ainda que esse método provavelmente seja indício da pouca familiaridade do poeta português com a prosódia e a métrica latinas, é, porém, testemunho seguro do engenho e originalidade com que resolveu um problema atinente à matéria em que era pouco versado. Como quer que seja, há trabalhos no estrito domínio da métrica clássica que estudam o número e a posição dos acentos de intensidade nalguns poetas - como, por exemplo, o já clássico de KNIGHT (1939) sobre Virgílio. No tocante à relação entre quantidade e intensidade silábicas em latim, vide passim Allen $(1973 ; 1965)$. 
Horácio que estão na base das odes heterométricas de Reis, noutros não é bem assim - donde se pode concluir, com alguma probabilidade, que a heterometria que pratica, partindo da simulação das tônicas de metros horacianos específicos, evolve para uma variação mais ou menos livre do modelo, criando novas combinações. Como sempre, no caso de um grande poeta a emular um par, o que Pessoa aprende, ao estudar as odes de Horácio, é antes de tudo e sobretudo um princípio de composição, que aplica livremente às suas necessidades particulares. À leitura, pois.

3.1) "Vem sentar-te comigo, Lídia, à beira do rio"

a) Contagem SiLÁbica tradicional [As marcações em negrito se referem a possíveis ditongações de certos hiatos: portanto, o número exato de sílabas poéticas nesses versos é duvidoso. O número à direita é o total de sílabas poéticas de cada verso.]

Vem sentar-te comigo, Lídia, à beira do rio.

Sossegadamente fitemos o seu curso e aprendamos 15

Que a vida passa, e não estamos de mãos enlaçadas. 13

(Enlacemos as mãos). $\quad 6$

Depois pensemos, crianças adultas, que a vida 12/13

Passa e não fica, nada deixa e nunca regressa, 13

Vai para um mar muito longe, para ao pé do Fado, 13

Mais longe que os deuses. 5

Desenlacemos as mãos, porque não vale a pena cansarmo-nos. 16

Quer gozemos, quer não gozemos, passamos como o rio. 15

Mais vale saber passar silenciosamente $\quad 12 / 13$

E sem desassossegos grandes. 8

Sem amores, nem ódios, nem paixões que levantam a voz, 16

Nem invejas que dão movimento demais aos olhos, 14

Nem cuidados, porque se os tivesse o rio sempre correria, 17

E sempre iria ter ao mar. $\quad 8$ 
Amemo-nos tranquilamente, pensando que podíamos, 15

Se quiséssemos, trocar beijos e abraços e carícias, $\quad 15$

Mas que mais vale estarmos sentados ao pé um do outro 15

Ouvindo correr o rio e vendo-o. 9

Colhamos flores, pega tu nelas e deixa-as $\quad 12$

No colo, e que o seu perfume suavize o momento - 12/13

Este momento em que sossegadamente não cremos em nada, 17

$\begin{array}{ll}\text { Pagãos inocentes da decadência. } & 10\end{array}$

Ao menos, se for sombra antes, lembrar-te-ás de mim depois 16

Sem que a minha lembrança te arda ou te fira ou te mova, 14

Porque nunca enlaçamos as mãos, nem nos beijamos 13

Nem fomos mais do que crianças.

E se antes do que eu levares o óbolo ao barqueiro sombrio, 16

$\begin{array}{ll}\text { Eu nada terei que sofrer ao lembrar-me de ti. } & 14\end{array}$

Ser-me-ás suave à memória lembrando-te assim — à beira-rio, $\quad$ 16/17

$\begin{array}{ll}\text { Pagã triste e com flores no regaço. } & 10\end{array}$

b) Número e posição dos AcEntos Intensivos [Tônicas em negrito. Os números à direita correspondem, respectivamente, ao total de tônicas, e ao número delas antes e depois da cesura principal. Em cada um dos versos marcados com asterisco foi assinalada a principal subtônica.]

Vem sentar-te comigo,| Lídia, à beira do rio.

$6(3+3)$

Sossegadamente | fitemos o seu curso e aprendamos $6(3+3)$

Que a vida passa, | e não estamos de mãos enlaçadas.

$5(2+3)$

(Enlacemos as mãos)*.

3

Depois pensemos, | crianças adultas, que a vida

$5(2+3)$

Passa e não fica, | nada deixa e nunca regressa,

$5(2+3)$

Vai para um mar muito longe, | para ao pé do Fado,

$5(3+2)$

Mais longe que os deuses*.

Desenlacemos as mãos, | porque não vale a pena cansarmo-nos. $\quad 5(2+3)$

Quer gozemos, quer não gozemos, | passamos como o rio. $5(3+2)$

Mais vale saber passar| silenciosamente

$6(3+3)$

E sem desassossegos grandes. 
Sem amores, nem ódios, | nem paixões que levantam a voz,

Nem invejas | que dão movimento demais aos olhos,

$5(2+3)$

Nem cuidados, | porque se os tivesse| o rio sempre correria,

$6(2+2+2)$

E sempre iria ter ao mar.

Amemo-nos tranquilamente, | pensando que podíamos,

$5(3+2)$

Se quiséssemos, | trocar beijos e abraços e carícias,

$5(2+3)$

Mas que mais vale| estarmos sentados | ao pé um do outro

$6(2+2+2)$

ouvindo correr o rio e vendo-o.

3

Colhamos flores, | pega tu| nelas e deixa-as

$6(2+2+2)$

No colo, e que o seu perfume| suavize o momento -

$5(3+2)$

Este momento| em que sossegadamente| não cremos em nada,

$6(2+2+2)$

Pagãos inocentes da decadência.

3

Ao menos, se for sombra antes, | lembrar-te-ás de mim depois

$6(3+3)$

Sem que a minha lembrança| te arda ou te fira ou te mova,

$6(3+3)$

Porque nunca enlaçamos as mãos,| nem nos beijamos

$5(3+2)$

Nem fomos mais do que crianças.

3

E se antes do que eu| levares o óbolo| ao barqueiro sombrio,

$6(2+2+2)$

Eu nada terei que sofrer| ao lembrar-me de ti.

$5(3+2)$

Ser-me-ás suave à memória| lembrando-te assim — à beira-rio,

$6(3+3)$

Pagã triste e com flores no regaço.

a) LEITURA ESCOLAR [Longas em negrito.]

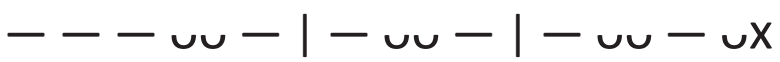

Tu ne quaesieris, | scire nefas, | quem mihi, quem tibi finem di dederint, | Leuconoe,| nec Babylonios temptaris numeros.| ut melius | quidquid erit pati. seu pluris hiemes | seu tribuit| Iuppiter ultimam, quae nunc oppositis | debilitat| pumicibus mare Tyrrhenum: sapias, | uina liques, | et spatio breui spem longam reseces. | dum loquimur, | fugerit inuida aetas: carpe diem, |quam minimum| credula postero. 
b) Número e Posição dos AcEntos Intensivos [Tônicas em negrito. A sequência dos números é a mesma do item b) da ode de Ricardo Reis.]

Tu ne quaesieris, | scire nefas, | quem mihi, quem tibi

$6(2+2+2)$

finem di dederint, | Leuconoe, nec Babylonios

$6(3+3)$

temptaris numeros.| ut melius quidquid erit pati.

$5(2+3)$

seu pluris hiemes seu tribuit| Iuppiter ultimam,

$5(3+2)$

quae nunc oppositis debilitat| pumicibus mare

$5(3+2)$

Tyrrhenum: sapias, | uina liques, | et spatio breui

$6(2+2+2)$

spem longam reseces.| dum loquimur, fugerit inuida

$5(2+3)$

aetas: carpe diem,| quam minimum credula postero.

$6(3+3)$

\section{ConCLUSÃo}

Lida segundo a escansão tradicional, a ode "Vem sentar-te comigo, Lídia, à beira do rio" - e com ela todas as heterométricas - aparece como exceção e irregularidade ocasional no seio da metrificação rigorosamente regular que caracteriza a maioria esmagadora das odes. Além disso, haja vista as tantas e tão evidentes manifestações de perfeição técnica que se podem observar no corpus de Ricardo Reis, as ditas irregularidade e exceção ocasional demandam uma explicação mais detalhada, sob pena de considerar-se mera falha ou imperícia do poeta.

Ao descobrir e publicar o Envelope 122, Fernando Lemos prestou um imenso serviço ao estudo do heterônimo Ricardo Reis, em geral, e, em particular, ao de suas odes heterométricas. Com efeito, antes de ter acesso ao conteúdo deste Envelope, a decifração do princípio compositivo, da tradição a que pertencem e da verdadeira novidade de tais experimentos métricos nos estava praticamente vedada, tamanha a escassez de dados que tínhamos à disposição. Uma vez publicado, porém, pudemos constatar o minucioso estudo empreendido pelo poeta, que, sobre haver se exercitado nos dois métodos principais de aclimatação de medidas clássicas ao português, cunhou também um método próprio, mapeando o número e a posição dos acentos de intensidade em vários metros e estrofes que Horácio praticou.

No tocante à ode em causa, o Envelope nos facultou encontrar o preciso metro de Horácio que esteve na base de sua composição - a saber, o asclepiadeu maior. De facto, basta comparar a incidência das tônicas e das cesuras principais em "Vem sentar-te comigo, Lídia, à beira do rio" e na ode I, 11 a Leucônoe para constatar que os versos mais longos daquela são 
clara tentativa de reprodução vernácula do metro desta, segundo o princípio da distribuição mais ou menos regular de cinco ou seis tônicas por verso. Já o verso mais curto, que à primeira vista poderia parecer outra exceção, explica-se facilmente pela frequência - praticamente uma regra nos metros de Horácio - com que o último verso de um quarteto ou bem é parte ou bem variação de um dos três que o precedem. O que confirma e corrobora, enfim, o que dissemos há pouco: quer os precisos metro e estrofe de Horácio que estão na base das odes heterométricas de Reis se identifiquem ou não, o que o poeta português aprende com o latino é um princípio compositivo e um técnica do verso, aprendizado que lhe faculta, segundo a (imensa) medida do seu engenho, apropriar-se do antecessor e variá-lo a seu talante. Do que a perfeição de "Vem sentar-te comigo, Lídia, à beira do rio" é prova eloquente.

Por último, parece-nos absolutamente factível que se achem as estrofes e metros de Horácio de que as demais heterométricas de Reis são decalques ou variações. Ocupando-se da maior e mais bem acabada delas, este breve artigo é uma primeira contribuição a esta obra por fazer. 


\section{REFERÊNCIAS}

Allen, W. S. Accent and Rhythm. Prosodic Features of Latin and Greek: a Study in Theory and Reconstruction. Cambridge: Cambridge University Press, 1973. . Vox Latina. A Guide to the Pronunciation of Classical Latin. Cambridge: Cambridge University Press, 1965.

Antunes, C. L. B. Métrica e Rítmica nas Odes Píticas de Píndaro. Tese de Doutoramento - Universidade de São Paulo, São Paulo, 2012.

BéLKIoR, SILVA. Texto Crítico das Odes de Fernando Pessoa-Ricardo Reis. Tradição Impressa Revista e Inéditos. Lisboa: Imprensa Nacional \& Casa da Moeda, 1988.

CAstilHo, A. F. DE. Tratado de Metrificação Portugueza: Seguido de Considerações sobre a Declamação e a Poetica. 5 ed. revista e augmentada. Porto: Livraria Moré-Editora, 1874.

CunHA, J. A. DA. Obra Literária. 2 Vols. Edição de Maria Luísa Malato Borralho e Cristina Alexandra Marinho. Porto: Campo das Letras. Vol. I, 2001; Vol. II, 2006.

KLIngner, F. Quintus Horatius Flaccus: Opera. 3. Auflage. Leipzig: Teubner, 1959.

KNIGHT, W. F. J. Accentual Symmetry in Vergil. Oxford: B. Blackwell, 1939.

Lemos, F. Fernando Pessoa e a Nova Métrica: a Imitação de Formas e Metros Líricos Greco-Romanos em Ricardo Reis. Mem Martins: Editorial Inquérito, 1993.

Magalhães de Azeredo, C. Odes e Elegias. Roma: Tipografia Centenari, 1904.

NogueIra, É. Verdade, Contenda e Poesia nos Idílios de Teócrito. São Paulo: Humanitas, 2012.

Nolasco DA CunHA, V. P. Sobre a Objecção do Snr. Bento Pereira á cerca da Syllaba Portugueza. O Investigador Portuguez em Inglaterra ou Jornal Literario, Politico, vol. 14, n. 54, novembro de 1815a.

. Consideraçoens sobre o Verso Saphico, e Principios Geraes da Syllaba, Applicados Particularmente á Lingoa Portugueza. O Investigador Portuguez em Inglaterra ou Jornal Literario, Politico, vol. 13, n. 52, outubro de 1815 b.

. O Investigador Portuguez em Inglaterra, vol. 7, n. 27, setembro de 1813.

Oliva Neto, J. A. \& Nogueira, É. O Hexâmetro Dactílico Vernáculo antes de Carlos Alberto Nunes. Scientia Traductionis 13: 295-311, julho de 2013.

PessoA, F. Obra em Prosa. Rio de Janeiro: Nova Aguilar, 1974. . Obra Poética. 3 ed. Rio de Janeiro: Nova Aguilar, 1969.

Submetido em: 10/02/2014

Aceito em: 03/04/2014 